OPEN ACCESS

Edited by:

Richard Burroughs, University of Rhode Island, United States

Reviewed by:

Marcus Geoffrey Haward, University of Tasmania, Australia

Christian T. K.-H. Stadtlander, Independent Researcher, St. Paul, MN, United States

*Correspondence:

Hollis R. Jones jones.r.hollis@gmail.com

Specialty section:

This article was submitted to Marine Affairs and Policy, a section of the journal

Frontiers in Marine Science

Received: 28 September 2020

Accepted: 14 December 2020

Published: 12 January 2021

Citation:

Jones HR, Briggs RA, Krepp A and Rohring E (2021) Strategies for Successful Research

to Application Projects: A Case Study of the National Sea Grant College

Program. Front. Mar. Sci. 7:610954. doi: 10.3389/fmars.2020.610954

\section{Strategies for Successful Research to Application Projects: A Case Study of the National Sea Grant College Program}

\author{
Hollis R. Jones ${ }^{1 *}$, Rebecca A. Briggs ${ }^{2}$, Alison Krepp ${ }^{2}$ and Elizabeth Rohring ${ }^{2}$ \\ ${ }^{1}$ Louisiana Sea Grant College Program, Louisiana State University, Baton Rouge, LA, United States, ${ }^{2}$ National Sea Grant \\ College Program, Oceanic and Atmospheric Research, NOAA, Silver Spring, MD, United States
}

As coastal landscapes change, management professionals are working hard to transition research results into actions that support scientifically informed decisions impacting coastal communities. This type of research faces many challenges due to competing priorities, but boundary spanning organizations can help mediate these conflicts by forming transdisciplinary collaborations. The National Sea Grant College Program (Sea Grant), a National Oceanic and Atmospheric Administration based agency, is a networked organization of 34 university-based state programs that uses a three pronged approach of research, extension, and education to move academic research into the hands of stakeholders and decision makers. The objective of this study is to better understand strategies for successful research to application (R2A) projects that address complex environmental problems occurring in a socio-economic context. Specifically, this work examines R2A projects from the Sea Grant network to better understand the drivers for project development and common deliverables produced through the R2A process. We identify five common facilitating factors that enabled 'successful' R2A across all projects: platforms for partnerships, iterative communication, transparent planning, clear examples of R2A, and graduate student involvement. By providing examples of successful frameworks, we hope to encourage more organizations to engage in the R2A process.

Keywords: transdisciplinary, coproduction of knowledge, research to application, stakeholder engagement, extension

\section{INTRODUCTION}

Coastal communities and ecosystems are facing multiple unprecedented challenges caused, in part, by increased urbanization, over exploitation of natural resources, climate change, and associated threats such as sea-level rise and increased extreme storm events (Nguyen et al., 2016; Stott, 2016). Resulting economic and cultural consequences are affecting food security, human health, and the communities that depend on the coasts' natural resources (Nelson et al., 2016). While urgency has grown to address the socio-economic and environmental consequences of anthropogenic influence and a changing climate, these complex environmental problems continue to be surrounded by uncertainty. Scientific research has been central to understanding and generating awareness of 
these challenges, but the essential next step of applying science to counteract these problems on the ground and in the communities in which they are occurring, has proven difficult (van Kerkhoff and Lebel, 2006). Strategies for transitioning science to application such as disseminating scientific information in lay terms, creating user friendly tools, engaging stakeholders, and developing and implementing management and mitigation strategies is often challenging and overlooked as an essential part of the scientific process.

Environmental threats are especially hard to address because they are influenced by biological, physical, and societal pressures; and solutions depend on the collaboration between scientists, policymakers, and the public (Lemos and Morehouse, 2005). These 'wicked' problems, first described in Rittel and Webber's (1973) article, occur in social contexts, and there is no single solution because the understanding of the problem is ever evolving (Rittel and Webber, 1973). To address complex environmental problems that are occurring in social contexts, research must move away from basic science toward a more integrated, applied, and decisiondriven approach (Gibbons, 2000; Lemos and Morehouse, 2005; Van Aken, 2005; Stokes, 2011). Applied science can be referred to by a variety of terms such as research to application (R2A), actionable science, or transdisciplinary science. The term transdisciplinary was first introduced in the 1970s and popularized in the 1990s as themes of sustainability and the global environmental crisis became prevalent; transdisciplinarity rejects the separation of topics into disciplinary silos and seeks to take a more holistic approach (Bernstein, 2015). Transdisciplinary approaches employ collaborations among scientists across disciplines and nonacademic stakeholders from business, government, and society for solution-oriented and socially conscious solutions (Lang et al., 2012). This type of research faces many challenges due to the competing priorities but boundary spanning organizations that coordinate and integrate activities across organizational contexts can help mediate these conflicts and increase the likelihood of successful R2A that utilizes transdisciplinary teams (Gibbons, 2000).

Scientific research that is used to manage complex environmental problems needs to be informed by the decision makers who use the science, as well as people and organizations who can affect, or be affected by, the use of the resulting science (i.e., stakeholders) (Arnstein, 1969). Cash et al. (2003) reports that projects that do not engage with stakeholder groups are less likely to succeed, and lays out a framework for improving the effectiveness of translating scientific information into action by making sure projects and their results are scientifically sound (credible), perceived as relevant to the needs of stakeholders (salient), and respectful (legitimate) in development (Cash et al., 2003).

Contributing to the complexity of environmental problems, there is a gap in how to translate and apply scientific information into real decision contexts (Iwamoto et al., 2019). Even the way that the term research-to-application is organized implies a linear process where knowledge comes first and underlies effective action. This pervasive way of viewing knowledge and action sequentially instead of simultaneously, is itself a barrier to solving complex environmental problems. Additionally, the term 'bridging the gap' implies that researchers (scientific knowledge) and practitioners (action) are two separate domains where the researcher is expected to develop knowledge that can then be applied to action to deliver solutions (West et al., 2019). Engaging in transdisciplinary research (Lang et al., 2012) the coproduction of knowledge (Miller and Wyborn, 2018) will be necessary to close the gap between research and application theories and actors.

Closing the gap between research and application (or knowledge producers and users) is especially imperative for research that is federally funded with the explicit purpose of solving societal problems (Matso and Becker, 2014). The National Oceanic and Atmospheric Administration (NOAA) is the federal agency that houses the National Sea Grant College Program (Sea Grant). NOAA and Sea Grant have both made research transitions a priority (National Oceanic and Atmospheric Administration, 2017).

We use the Sea Grant as an exploratory case study (Yin, 1981) to examine strategies for successful R2A projects. Defining success requires determining a set of objectives to accomplish; this process is extremely context dependent and one stakeholder's success story may very well be another's failure (Hilborn, 2007). Within the context of this paper success is self-identified, meaning that there is no one common objective to accomplish or metric for success. We ask three main questions: (1) Do 'successful' R2A projects more often start with scientific inquiry or stakeholder need?, (2) What deliverables are commonly created by 'successful' R2A projects?, and (3) Which facilitating factors that enable 'successful' R2A are already being utilized by the Sea Grant network? The bulk of discussion elaborates upon the facilitating factors, or strategies, for R2A: platforms for partnerships, iterative communication, transparent planning, clear examples of R2A, and graduate student involvement. The discussion of these R2A strategies is intended to encourage more organizations to engage in the $\mathrm{R} 2 \mathrm{~A}$ process.

\section{Background on National Sea Grant College Program}

The Sea Grant, was established by the United States Congress in 1966. Sea Grant consists of a federal/university partnership between NOAA and 34 university-based programs in every coastal and Great Lakes state, Puerto Rico, Guam, and the National Sea Grant Library. Sea Grant's mission is to enhance the practical use and conservation of coastal, marine and Great Lakes resources in order to create a sustainable economy and environment. This is accomplished through a network that draws on the expertise of thousands of scientists, community engagement specialists, educators, and students. Sea Grant uses a three pronged approach of research, extension, and education to move academic science up the Scale of Public Participation from informing to consulting, involving, collaborating, and eventually empowering stakeholders through two-way communication that allows stakeholders to directly influence decision making (Figure 1). 
This three pronged approach is facilitated by an expansive communications community, which allows Sea Grant to create knowledge to action networks to meet coastal stakeholder and ecosystem needs.

\section{Research}

University-based Sea Grant programs tailor specific research priorities to the need of their state, which is informed through extensive feedback with stakeholders. The programs then fund biennial or annual competitive research competitions to address research needs. In 2018, state Sea Grant programs funded over 300 proposals and the Sea Grant network as a whole supported over 1,500 researchers and 1,000 graduate students. Sea Grant's programmatic model enables basic and applied research to be leveraged by the Sea Grant Extension and Education Network (National Sea Grant Office, 2019). Each state program employs a Research Coordinator (RC) who is responsible for coordinating the development, expansion, delivery, and reporting of their state program's research competitions and fellowships.

\section{Extension}

Sea Grant extension staff are known by many names - specialist, educator, researcher, marine advisor or agent - with the overarching goal of these professionals being to engage with their stakeholders to improve the relevancy and utility of Sea Grantfunded research (National Sea Grant Office, 2000). In 2018, Sea Grant either directly employed, or collaborated with nearly 600 extension professionals that live and work in the communities they serve, and have long-term relationships with the community and their local partners. Extension professionals are considered to be trusted members of their communities who provide sciencebased information on complex or controversial scientific topics. By being a part of the community they serve, they are able to help Sea Grant and university researchers identify needs and research gaps. Sea Grant extension staff can develop projects beyond a grant's funding period and this, along with the linked network of regionally based state Sea Grant programs, enables Sea Grant to tailor itself to address regional needs. Similar to the RC role, each state program also employs an Extension Lead (EL) who is responsible for the programmatic management of Sea Grant extension faculty, staff, and their activities.

\section{Education}

The goal of Sea Grant education is to bring ocean, coastal, and Great Lakes science literacy to the United States population. Sea Grant's education portfolio includes undergraduate and graduate training, teacher education, K-12 curriculum development, fellowships, informal education for the general public, and special training programs for industry. Educators work closely with universities, the NOAA Office of Education, the National Marine Educators Association and other partners to develop formal education programs, workforce training and professional education programs.

\section{MATERIALS AND METHODS}

To better understand strategies for integrating research and extension for more successful R2A across the Sea Grant network, semi-structured interviews were conducted with the state Sea Grant program RCs and ELs. At the time of the interviews,

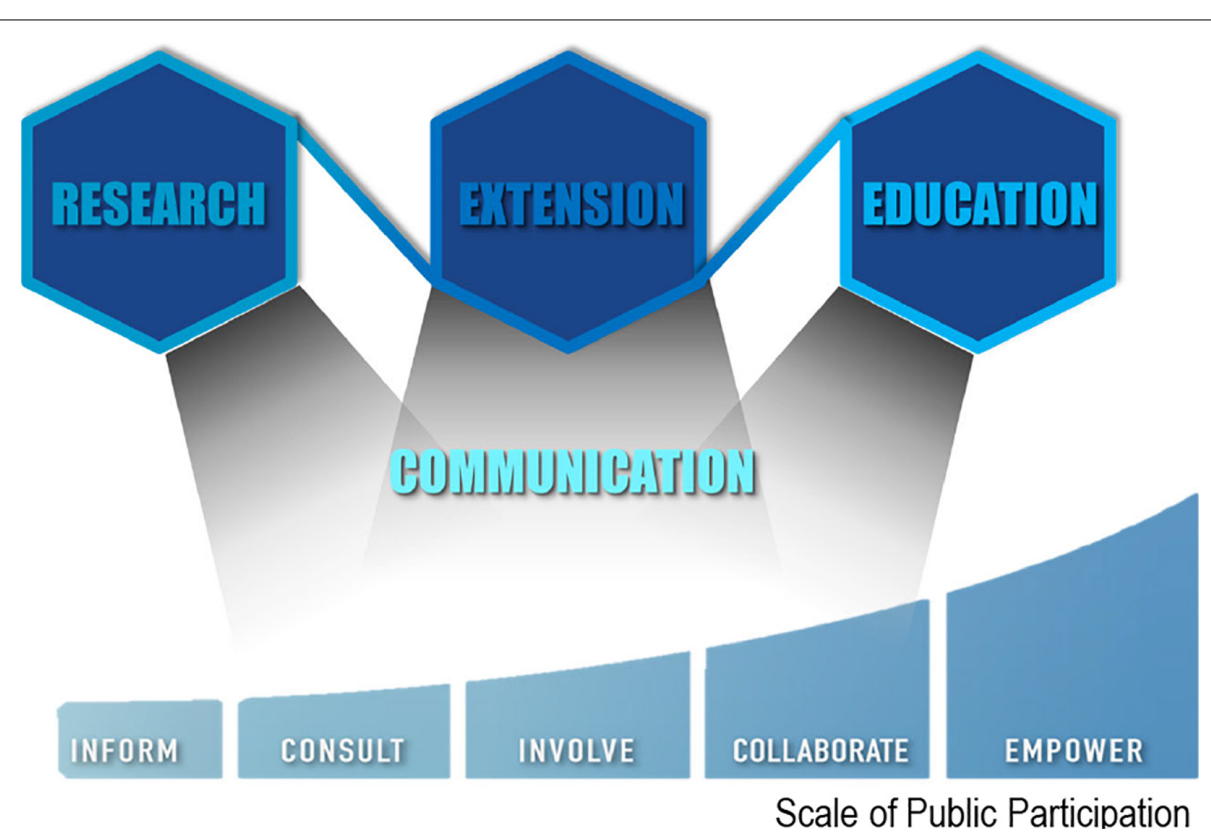

FIGURE 1 | The Sea Grant Model. The National Sea Grant College Program links research, extension, and education through active and iterative communication to involve stakeholders and partners in two-way communication to move up the Scale of Public Participation from inform to consult, involve, collaborate, and eventually empower. Adapted from Maine Sea Grant. 
the interviewer (Jones, H) was affiliated with Louisiana State University so their Office of Research \& Economic Development was contacted and it was decided that this project was considered to be a "scholarly activity" that did not require IRB approval. Semi-structured interviews were used because they allow for greater freedom in the sequencing, exact wording of questions, and can be guided by the interviewees' responses. Interviews typically lasted 30-45 $\mathrm{min}$ and were based on ten guiding questions. The order of the questions changed on an individual basis, but each interview was consistently guided by the following overarching framework with the intention of understanding (1) how programs design and promote their research competitions, (2) what challenges to R2A the interviewee has experienced in their role as a $\mathrm{RC}$ or $\mathrm{EL}$, and (3) what is an example of a R2A project that was funded by their state Sea Grant program that integrated Sea Grant extension and research that they think was particularly 'successful', and why. The answers provided by the interviewee were transcribed, summarized, and analyzed.

The RCs and ELs from 33 state Sea Grant Programs were contacted for semi-structured, open-ended interviews. Interviews with $25 \mathrm{RCs}$ and $27 \mathrm{ELs}$ (52 total interviews) were completed between March and September 2019. Interviews with both the RC and the EL were completed for 22 programs, only the RC for three programs, only the EL for five programs, and no interviews for three programs. Most interviews were conducted via video conferencing (44 interviews), but five were over the phone and three were in-person. Video conferencing was our preferred platform but phone calls were used when our video conferencing platform wasn't working. When an in-person visit to the Sea Grant program was already planned, we took the opportunity to conduct the interview with the RC or EL then.

We emphasize that the conversations are retroactive opinions about projects where the interviewee is incentivized to identify success and are therefore limited. Additionally, different stakeholder groups have a broad range of objectives that may be conflicting. The resulting initiation strategies, deliverable categories, and facilitating factors formulated from the 52 interviews are by no means comprehensive or concrete but, it is fundamental that we learn from past experience and apply lessons learned to future R2A projects (Hilborn, 2007).

\section{RESULTS}

After interviews were completed, transcript data was compiled and reviewed to address three primary questions that provide a foundation for how the Sea Grant model is utilized to support and execute successful R2A projects.

\section{Do 'Successful' R2A Projects More Often Start With Scientific Inquiry or Stakeholder Need?}

When discussing the $\mathrm{R} 2 \mathrm{~A}$ project examples, the mode of project initiation as scientific inquiry or stakeholder need was designated by the interviewee. Stakeholder need was defined as the project idea originating with an individual or organization (e.g., stakeholder) outside of the core researcher who applied for Sea Grant funding; whereas scientific inquiry was defined as being formulated solely by the researcher applying for the funding.

The RCs identified 25 projects and the ELs identified 27 projects, as 'successful' R2A. 'Success' was self-identified within the definition of application as, information products, assessments, and tools used in decision making and resource management that enhances stakeholder ability to avoid, mitigate, or adapt to new threats or risks (National Oceanic and Atmospheric Administration, 2017). Of the 52 'successful' research projects, 30 were identified to have originated from scientific inquiry, and 22 from stakeholder need (Figure 2). RCs identified 16 projects that started with scientific inquiry and nine projects that started with stakeholder need; whereas ELs identified 14 projects that started with scientific inquiry and 13 projects that started with stakeholder need (Figure 2). More RCs identified projects that start with scientific inquiry as 'successful' and more ELs identified projects that start with stakeholder need as 'successful.' This is likely because RCs are more familiar with the researchers and their projects, whereas ELs are more connected to extension projects and results.

\section{What Deliverables Are Commonly Created by 'Successful' R2A Projects?}

The most salient deliverable was designated by the interviewee when discussing the $\mathrm{R} 2 \mathrm{~A}$ project examples. While many projects had multiple outcomes that could have been categorized into a number of categories, to simplify the categorization, the most salient outcome/deliverable was used to develop the categorization presented in this paper. The five broad categories of Sea Grant programmatic R2A deliverables developed from the interviews include: information production, attitude change, behavioral change, informing policy, and tool operationalization (see Table 1 for descriptions). These categories were formulated after assessing the identified deliverable from each project and comparing them to the previously stated NOAA definition of an application to assure agency relevance.

The 52 total projects from the interviews were categorized into one of these R2A deliverable categories using their most salient deliverable (Figure 3). Of the 27 projects identified by ELs, the most commonly identified deliverable was tool operationalization (eight projects), while attitude change was identified the lowest number of times (three projects) (Figure 3). Of the 25 projects identified by RCs, the most commonly identified deliverable was information production (seven projects), while informing policy was identified the lowest number of times (three projects) (Figure 3). ELs identified more projects in tool operationalization and informing policy, while RCs identified more projects in information production, behavioral change, and attitude change. The largest difference between RCs and ELs is the informing policy category; three projects are identified by RCs and seven projects are identified by ELs. This is likely because ELs are more involved in and aware of projects informing the policy process. 


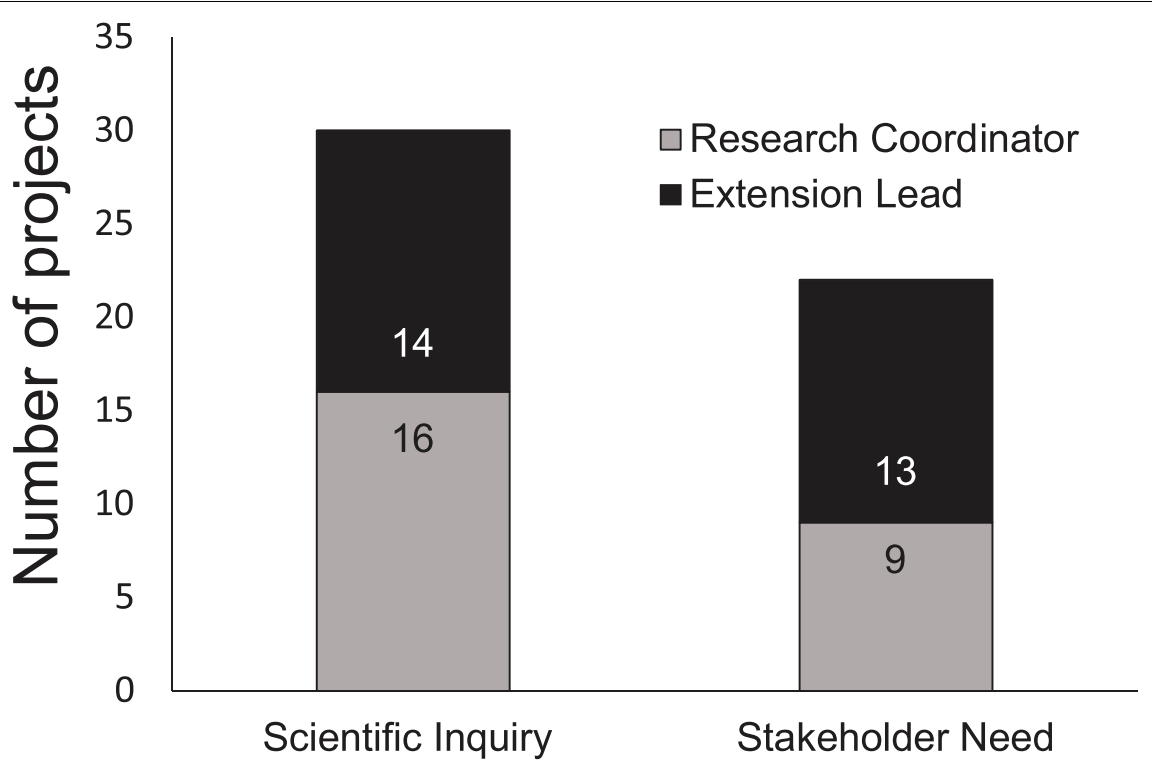

FIGURE 2 | The 52 examples of 'successful' research to application (R2A) projects identified by Research Coordinators (RCs) and Extension Leads (ELs) categorized by whether they were initiated by scientific inquiry or stakeholder need. Projects identified by RCs are in gray while projects identified by ELs are in black. Numbers within bars represent how many projects fall into each category.

\section{Which Facilitating Factors That Enable 'Successful' R2A Are Already Being Utilized by the Sea Grant network?}

Common themes in the interview transcripts were summarized into strategies (defined hereafter as facilitating factors) that enable successful research and extension integration across the Sea Grant network. The qualitative process to formulate the facilitating factors began by assigning at least one 'best practice' to each individual example of an $\mathrm{R} 2 \mathrm{~A}$ project by asking the interviewee "what do you think made this project so successful?" and recording the answers. This deliberate self-identified 'success'

TABLE 1 | Five common research to application (R2A) project deliverables, identified and categorized from interview data.

\section{R2A deliverables}

Information production The production of information or assessments without a clear step beyond informing stakeholders

Attitude change

Scientific information products or tools produced to inform that result in a change of stakeholder attitude or perspective on an identified problem

Behavioral change

Scientific information, products, or tools with visible incentives or processes to effect a stakeholder's actions or routine

Informing policy

Scientific information, products, or tools provided to decision makers to inform a decision that could result in policy change

Tool operationalization Development of tools (mechanical or digital) that can be used by stakeholders to understand or address an identified problem

Descriptions are grounded in Sea Grant programmatic goals as well as the NOAA definition of an application. provides a better understanding of EL and RC perspectives. Selfidentified 'best practices' were qualitatively categorized to identify common themes that were summarized into the five facilitating factors. The facilitating factors were formulated after completing all interviews with Sea Grant RCs and ELs, and determined regardless of how the project was initiated or what the final deliverable was, indicating their importance and applicability to the $\mathrm{R} 2 \mathrm{~A}$ process.

Strategies for improving R2A success were categorized into five facilitating factors: platforms for partnerships, iterative communication, transparent planning, clear examples of R2A, and graduate student involvement. See Table 2 for descriptors of each facilitating factor. These factors, along with associated Case Studies from the Sea Grant network, are reviewed in detail in the Section "Discussion."

\section{DISCUSSION}

A changing climate is shifting the way we do science and requires boundary spanning programmatic approaches that are capable of developing and executing successful R2A projects to address the complex environmental problems facing our society. For over 50 years, Sea Grant's statutory mandates and programmatic feedback loops have connected community needs with scientific research and provides an ideal case study to evaluate what members view as best practices for R2A success. From 2010 to 2018, the National Sea Grant College Program received an average congressional appropriation of $\$ 79 \mathrm{M}$ per a year and aimed to allocate $40 \%$ of this to competitive research. Over these 9 years the funds were distributed across research ( $37 \%$ on average), extension ( $31 \%$ on average), and 


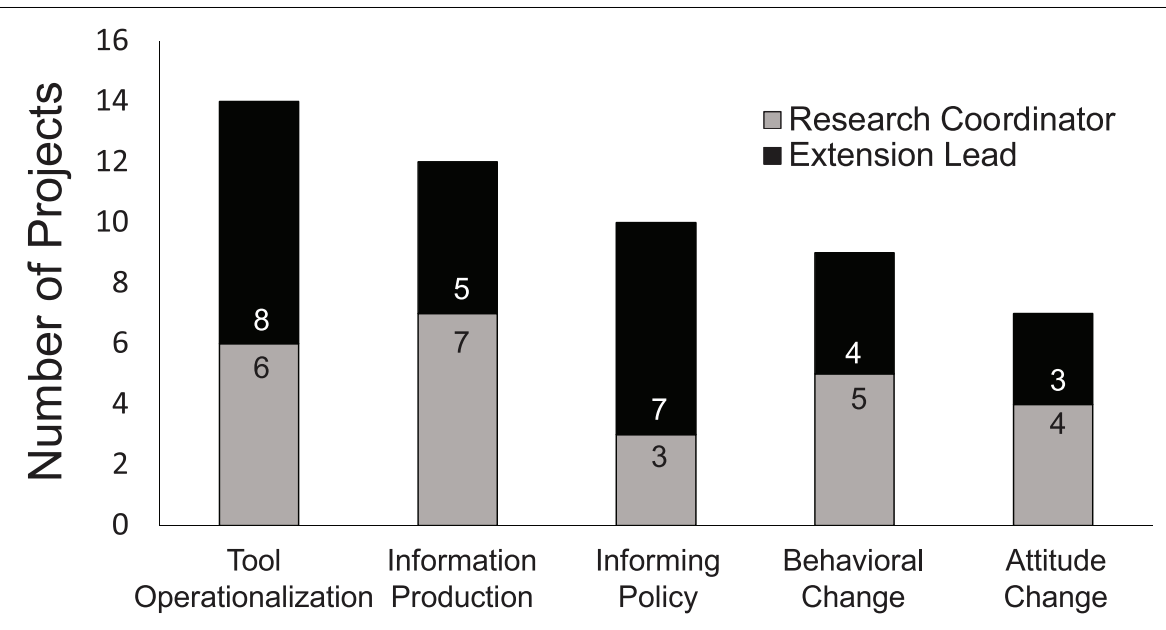

FIGURE 3 | The 52 examples of 'successful' research to application (R2A) projects identified by Research Coordinators (RCs) and Extension Leads (ELs) categorized by their most salient deliverable. Projects identified by RCs are in gray while projects identified by ELs are in black. The five categories are: tool operationalization, information production, informing policy, behavioral change, and attitude change. Numbers within bars represent how many projects fall into each category.

education (5\% on average), with the remainder used for core functions of management and communication (Figure 4). This distribution of funds between competitive research and extension provides the core investment structure essential for establishing a programmatic framework that enables successful R2A. This study further explores the Sea Grant program model, through the functional perspectives of the RCs and ELs, and its ability to effectively facilitate the $\mathrm{R} 2 \mathrm{~A}$ process through convening transdisciplinary teams including Sea Grant researchers and extension professionals. By better understanding and sharing transition strategies, deliverables, and challenges within the R2A process, a framework can be established for the co-production of knowledge to translate and apply scientific information into real decision contexts.

We emphasize that the conversations about R2A success are all retroactive opinions and are therefore limited. We first asked whether 'successful' R2A projects more often start with scientific

TABLE 2 | Facilitating factors were identified from the analysis of interview transcripts based on their ability to enable research and extension integration for 'successful' research to application as reported by the interviewee.

\section{Facilitating factors}

Platforms for partnerships Time, space, and structure for the formation of transdisciplinary teams among scientists and non-academic stakeholders.

Iterative communication Continuous, multi-directional dialogue before, during, and after a project.

Transparent planning Defined and detailed outreach and engagement plans that involve holistic problem framing.

Clear examples of R2A Accessible examples and models for developing actionable science in partnership with Sea Grant extension.

Graduate student involvement inquiry or stakeholder need and found that of the 52 'successful' research projects, 30 were identified to have originated in scientific inquiry and 22 in stakeholder need (Figure 2). One reason for the higher proportion of projects initiated with scientific inquiry could be because this is a historically more common approach to competitive research, and therefore an

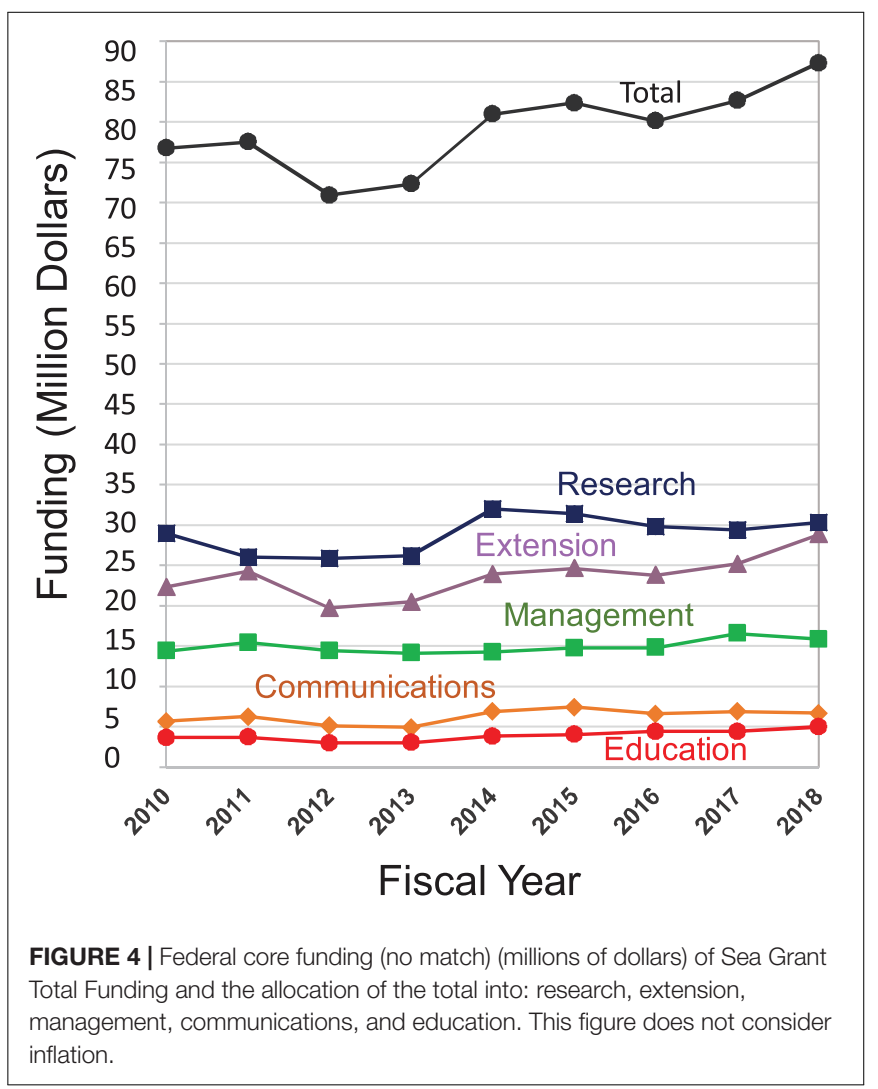


overall higher number of projects are designed this way. RCs were slightly more likely to identify scientific inquiry as the project origin (16 vs. 14), while ELs were more likely to identify stakeholder need (13 vs. 9) (Figure 2). This correlation is most likely due to the RC or EL placing, respectively, higher value on academic researcher or extension involvement in a project, based on their relationships and exposure to scientific investigators and extension staff. But, it is apparent that regardless of the RCs' and ELs' background and priorities, both avenues for actionable science are considered 'successful' and a program model like Sea Grant, that supports integration of these research and extension functions, is significant in facilitating successful R2A.

Next, we asked what deliverables are commonly created by 'successful' R2A projects and found that out of the $52 \mathrm{R} 2 \mathrm{~A}$ projects tool operationalization is identified most often (14 times), while attitude change is identified the least (seven times) (Figure 3). Tool operationalization encompasses a wide variety of products that serve the diversity of Sea Grant end-users and was identified $29.6 \%$ percent of the time by ELs and $24 \%$ of the time by RCs, indicating its importance to both RCs' and ELs' definition of success (Figure 3). Tool operationalization directly relates to the Sea Grant extension mission to translate science-based solutions to be understandable and useful to coastal stakeholders, and could be why the ELs were more likely to identify these R2A projects as successful. This result also indicates that Sea Grant projects are completing the R2A process and achieving their goal of serving end users with applicable tools.

The breadth of program design and structure within the Sea Grant network provides a rich suite of localized case studies to draw upon our understanding of the key elements that facilitate the $\mathrm{R} 2 \mathrm{~A}$ process. To further understand what made projects 'successful,' we asked which facilitating factors that enable 'successful' R2A are already being utilized by the Sea Grant network and identified five R2A facilitating factors (Table 2). These facilitating factors provided a framework for how to execute successful R2A, and are individually discussed below. A case study from the Sea Grant network accompanies each facilitating factor, showcasing how Sea Grant programs implement these R2A enabling strategies to overcome the challenges associated with R2A. These case studies by no means cover the breadth of approaches to facilitating R2A but provide examples that can be adapted by other programs and organizations.

\section{Facilitating Factors \\ Platforms for Partnerships}

The facilitating factor platforms for partnerships is characterized as the elements related to the time, space, and structure for the formation of transdisciplinary teams among scientists and non-academic stakeholders (Table 2). Addressing complex environmental problems requires the formation of transdisciplinary teams (Whitmer et al., 2010) but, these relationships do not form in a vacuum and cannot be effective simply by mandate. Sea Grant brokers and engages in partnerships at the national and local level with communities, businesses, local governments, academic institutions, and state/federal agencies. This partner rich model enables it to leverage its relatively small staff and budget by drawing on the expertise of more than 3,000 scientists, decision-makers, engineers, public outreach experts, educators, and students for increased impact.

State Sea Grant programs form extensive partnerships throughout the state with local, state, and federal agencies to meet strategic priorities. Partnerships at the state level begin with the stipulation that each state Sea Grant program is associated with one or more university within that state. The university-partner relationship is a structural platform that provides fiscal stability through 4-year cooperative agreements with NOAA, positioning the state program and empowering staff with an increased ability to build time, space, and structure for partnerships between university researchers and local stakeholders.

While forcing people to work together can lead to disengagement, incentivizing the involvement of the extension workforce throughout an R2A project can help incorporate end user needs and the continuation of project deliverables after the funding cycle is complete. Sea Grant extension provides a variety of platforms, such as time and space, that researchers can use to form partnerships and tap into a wealth and community of knowledge to produce needed science, in a usable format, based on mutual trust and respect. Facilitating partnerships between these two areas of expertise builds social capital and cross science literacy for successful R2A.

Case study from the Sea Grant Network: The Louisiana Sea Grant has developed a successful platform for building partnerships between researchers and extension with the Louisiana Discovery, Integration and Application (LaDIA) Fellows Program ${ }^{1}$. The LaDIA Fellows Program, is available to tenure track faculty conducting research in coastal Louisiana. Over the course of a year, Fellows participate in three retreats that help them expand their ability to address coastal challenges. These retreats provide time, space, and structure for participants to connect with Louisiana legislatures, commercial fishermen, city planners, tribal members, and residents in order to gain a new perspective on how coastal issues affect these communities. Louisiana has a complex coastal social-ecological landscape, and this face-to-face exposure can help new faculty members (that may be new to the area) improve their understanding of coastal issues in the Gulf of Mexico. Talking to a city planner that is considering new infrastructure to combat sea level rise, or hearing from a commercial oyster fisherman that has been affected by a freshwater river diversion, can help researchers contextualize their coastal research and provide a platform for partnerships and collaborations with end users.

\section{Iterative Communication}

The facilitating factor iterative communication is characterized as continuous, multi-directional dialogue before, during, and after a project (Table 2). Active and inclusive communication is a key element that helps transdisciplinary teams tap into stakeholder need and build trust to produce relevant, timely,

\footnotetext{
${ }^{1}$ https://www.laseagrant.org/outreach/ladia/fellowships/
} 
and accessible science (Hering, 2016); this continuous process is highlighted in Figure 5. One of the most commonly identified challenges to R2A by the state Sea Grant RCs and ELs was poor communication and the resulting lack of trust and respect between disciplines and positions. Interviews revealed that this process can be prohibitively time consuming, especially when imposed on project teams operating under traditional research grant project periods or within conventional research program models. Iterative communication requires adequate time and resources for in-depth engagement with stakeholders throughout the project duration and is built into Sea Grant's program model on two levels: national and local. At the national level, program resources are allocated over 4-year awards to the state programs, allowing for longer term planning and project development. At the local level, extension staff live and work in the communities they serve, providing the engagement foundation necessary for partner and stakeholder input. This tiered approach innovates beyond the research-need meets research-funding paradigm because the two levels inform each other to form a feedback loop that further builds trust and an understanding of national and local priorities across the Sea Grant network.

Every 4 years the National Sea Grant Office and its Federal Advisory Committee, as well as the state Sea Grant programs and their local partners, engage in strategic planning to establish programmatic priorities. This process integrates and aligns national priorities identified by NOAA with local needs and values identified by state Sea Grant programs and their stakeholders. In this way, stakeholder values are incorporated into national and state strategic plans, which establish the overarching framework used for iterative communication throughout the program's 4-year planning cycle and across its

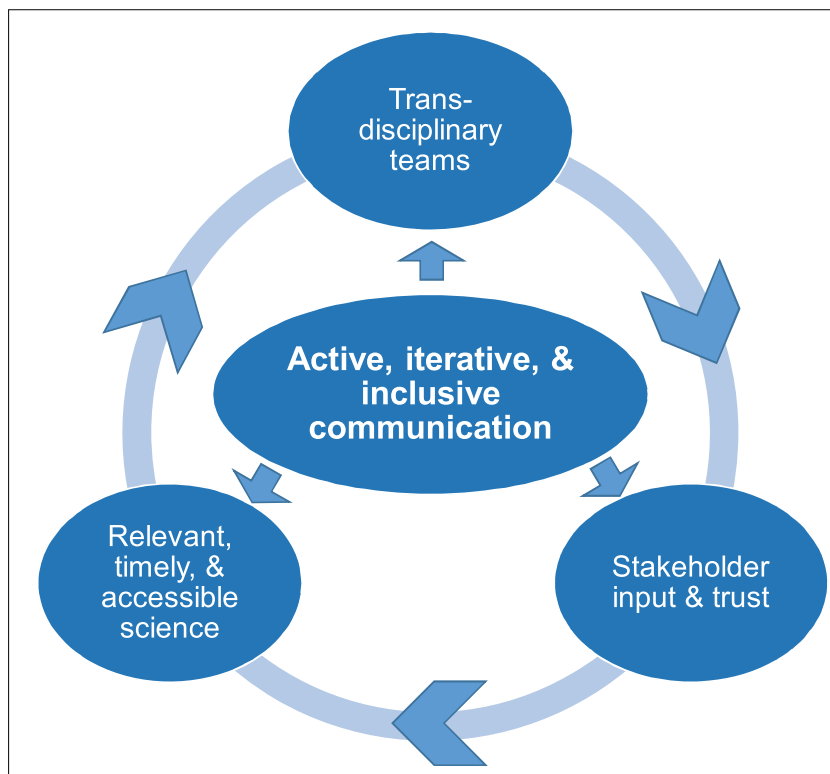

FIGURE 5 | The Sea Grant process for active and inclusive communication that uses transdisciplinary teams to tap into stakeholder need and build trust to produce relevant, timely, and accessible science. functional areas, including research and extension. Importantly, this includes the state Sea Grant program's research competitions and associated funding decisions.

One way that state Sea Grant programs promote a process of iterative communication is by developing platforms that allow researchers to discuss their ideas and explore potential collaborations with Sea Grant extension staff, communicators, and/or partners. These platforms are varied across the network but can include kick-off meetings, research symposia, or set office hours for meet-and-greet opportunities. These activities have been successful in facilitating iterative communication throughout the development and, if funded, the subsequent duration of a project.

Extension professionals are a fundamental pathway and key tool that facilitate iterative communication in the Sea Grant model. Extension staff play an essential role in connecting endusers with academic research or facilitating workshops focused on convening key partners and stakeholders to get input and share information. Because extension staff serve in a long term capacity (vs. short term funding cycles) they are able to execute the application element of $\mathrm{R} 2 \mathrm{~A}$ projects beyond the typical funding cycle of an average research project. The longevity of these positions also allows extension staff to build strong bonds with the community, especially among groups with competing priorities.

Case study from the Sea Grant Network: While there are numerous examples from the Sea Grant network of iterative communication between researchers, extension staff, stakeholders, and decision-makers, one example that demonstrates just how complicated and time consuming this process can be is the "Assessing the Risk of 100-year Freshwater Floods in the Lamprey River Watershed of New Hampshire Resulting from Changes in Climate and Land Use" project funded in part by New Hampshire Sea Grant. The goal of this project was to create relevant, useful, and accessible flood maps. Throughout the project, an Advisory Committee and focus groups were convened to provide iterative feedback on the usability of the maps. Because of the use of transdisciplinary teams that regularly shared information in a trusted environment, the produced maps are now commonly used by the end-user community. This project also spurred an economic, legal, and social analysis over the course of almost a decade - accentuating how long it can take for collaborative, transdisciplinary science to conclude. More information about this project can be found at http://100yearfloods.org/.

\section{Transparent Planning}

The facilitating factor transparent planning is characterized as defined and detailed outreach and engagement plans that involve holistic problem framing (Table 2). This process involves iterative communication, but the emphasis is on activities before the research funding is awarded to clarify roles and responsibilities that improve project design. In the Sea Grant model, transparent planning begins with an open and inclusive strategic planning process. As previously discussed, Sea Grant's strategic plans are grounded in stakeholder need which establish favorable conditions for a higher likelihood of actionable science that is 
timely, relevant, and accessible (see Iterative Communication for more information on Sea Grant's strategic planning process).

Sea Grant employs staff and uses its program structure to encourage thoughtful planning and transparency. This is evident in our analysis of individual program competition documents, which provide detailed, clear, and transparent guidance for potential applicants. Over the course of its 50-year history, Sea Grant programs have learned to write and structure their competition guidance documents as a planning tool that can be used by their applicants to avoid expectation mismatches between the funding program, researchers, and collaborative partners. Traditionally, funding agencies design their proposal calls with a focus on the research deliverable, not its application. A paradigm shift that presents researchers with a framework that defines and guides their work such that a project's technical rigor and effective application can be fully integrated into its evaluation is needed. Transparent guidance documents that articulate what successful outreach and engagement looks like, in combination with increased accessibility to Sea Grant staff and resources, provide avenues for a higher likelihood of successful R2A.

Case study from the Sea Grant Network: Oregon Sea Grant helps facilitate transparent planning for their funding applicants by providing a "Developing Outreach Plans and Effective Partner Engagement" guidance document. This research competition guidance document on what successful outreach and engagement looks like starts with clear definitions of outreach, audience, outreach plan, partner engagement, project partners, and stakeholders. It also provides clear statements of what Oregon Sea Grant is looking for in a research proposal and how it will be evaluated. This kind of structure within the research competition guidance, in combination with clear examples of R2A transitions, can increase the likelihood of science usability. This document is available online at: https://preview.tinyurl.com/r4sz4ys.

\section{Clear Examples of R2A}

The facilitating factor clear examples of $R 2 A$ is characterized as providing accessible examples and models for developing actionable science (Table 2) which in the context of this study occur in partnership with Sea Grant extension. This facilitating factor supports transparent planning for future research funding competitions but also requires the commitment of program staff to catalog and share successful (or unsuccessful) narratives and strategies in past R2A projects. There is a wealth of literature discussing case studies that attempt to link R2A with the intention of identifying strategic integration approaches (Cash et al., 2003; National Research Council, 2006; Matso and Becker, 2014). These published case studies are useful from an academic perspective, but for place-based funding programs like Sea Grant, locally scaled examples may be more relevant. Providing clear examples and avenues for developing actionable science in partnership with Sea Grant extension can be especially helpful for researchers that may not have training in skill areas foundational to R2A such as outreach and engagement.

Since 2010 the Sea Grant network has been promoting successful R2A by soliciting each program to put forward their best R2A projects. Every 2 years a project is selected to celebrate R2A success and share examples - making actionable science something to work for instead of incidental. At the state level, Sea Grant programs host and share R2A successes with prospective researchers through several different platforms such as webinars and 'kickoff meetings.' During which, many state programs will invite extension staff, communicators, new researchers, and past researchers to participate and share their expertise, interests, and success stories. While this level of involvement before research proposals are submitted is a heavy lift for the funding program, it can improve the use and reach of federal research funds.

Case study from the Sea Grant Network: Texas Sea Grant provides examples of past R2A projects and strategies for success by hosting an optional "Integrating Research and Extension Full Proposal Workshop" for researchers that have been encouraged to submit full proposals. This workshop introduces the Texas Sea Grant Extension Team, their locations, and Texas specific examples of research and extension integration. These examples include facilitation, workshops, training, and technical assistance. This workshop can be attended remotely to encourage inclusivity despite distance barriers. Visit texasseagrant.org/funding/research-funding/requestsfor-proposals for more information and updates about proposal workshops.

\section{Graduate Student Involvement}

This study characterizes the facilitating factor graduate student involvement as providing internships, shadowing, mentoring, and training to empower future researchers to conduct actionable science (Table 2). Graduate student training is no longer seen as a purely academic and isolated process (Gemme and Gingras, 2012). Students are increasingly expressing a desire to give back to their communities by having an impact on local, regional, and national management and policy (Nyden, 2003). This kind of experiential learning is an exciting trend in higher education and an opportunity for organizations like Sea Grant to lead the way in training early career researchers in how to produce more relevant and usable research. Sea Grant has also made supporting students from a diversity of backgrounds and perspectives a priority to work toward an academic field that reflects the communities that it serves. This early intervention could also help address the perception that academic researchers are not interested in, or trained to conduct actionable science.

Engaging graduate students in partnerships with organizations and mentors outside of academia is mutually beneficial - with the student gaining professional skills and connections, and the organization benefiting because of the potential for future employment of a versed transdisciplinary researcher. In 2018, Sea Grant supported 1,994 undergraduate and graduate students. Many state Sea Grant programs require that their funded graduate students have two advisors: their academic research advisor and an advisor from an outside agency (ex: Department of Natural Resources or a member of industry). This dual advising ensures that the results of the student's work are directly delivered to the appropriate decision makers, and forms potentially lasting partnerships and experience communicating and working with organizations outside of academia that have been isolated in the past by 
professional norms and specialized languages (Schaffner et al., 2016). Sea Grant is increasing the likelihood of a future with well-trained scientists that possess the skills necessary to form transdisciplinary teams to transition R2A by coordinating these educational opportunities and providing the space, time, and structure for partnerships to form.

Case study from the Sea Grant Network: Virginia Sea Grant spends the majority of its federal competitive research dollars on graduate student funding and requires that the students that they fund maintain an academic and professional mentor. Students are expected to work alongside their professional mentor to complete outreach plans and participate in at least one professional development training/event every year. Virginia Sea Grant coordinates the orientation meeting with students, academic, and professional mentors and regular professional development opportunities. These kinds of stipulations that are incentivized by funding can better train graduate students and prepare them for a transdisciplinary future. Visit the Virginia Sea Grant Fellowships \& Research Funding page ${ }^{2}$ and Professional Development page $\mathrm{e}^{3}$ to learn more.

\section{Challenges and Recommendations}

During the interview process, RCs and ELs identified the following challenges as barriers to full realization of the R2A process: (1) academic researchers' lack of interest in engaging in actionable science, (2) lack of training in conducting actionable science, and (3) a general lack of avenues for communication between stakeholders. To overcome these barriers to the R2A process, there is a responsibility for Sea Grant, and other federal funding programs, to empower researchers with the necessary resources and skills to transition academic research into the community and into the hands of decision makers. There are several approaches that can address these challenges (van Kerkhoff and Lebel, 2006), however, during this study, the Sea Grant RCs and ELs clearly identified future priority actions for funding agencies. Three actions are discussed in more detail below: post-project tracking, skill development, and providing larger funding pools with longer funding cycles.

\section{Post-project Tracking}

Conventionally, project tracking does not continue beyond a grant's funding period hindering the ability to fully capture measurable societal impacts. Research impacts are often nonlinear and can take a decade or longer before they can clearly demonstrate an application (Riley et al., 2011) and evolving current systems to include post-project tracking is vital to capture a project's complete impact. While project tracking and reporting can be perceived as burdensome for researchers, it is critical in the larger scope to ascertain what makes a R2A project 'successful,' the longevity of that 'success', and ultimately to more effectively institutionalize the factors that promote impactful R2A outcomes.

\footnotetext{
${ }^{2}$ vaseagrant.org/fellowship-research-funding/fellowships

${ }^{3}$ vaseagrant.org/professional-development
}

\section{Skill Development}

Investing in the communication, engagement, and facilitation skills necessary to engage partners in the coproduction of knowledge is essential to ensure mutual professional respect and promote the cross-science literacy needed to integrate different disciplines of knowledge. Opportunities to develop new skills can be few and far between as people progress through their career, and in academic settings the bias to value publication rates over demonstrated societal impacts continues to persist. The Sea Grant network is well-positioned at the university-community interface to advance the R2A capacity of research teams, including academic researchers and Sea Grant extension with early and mid-career training in collaborative process skills.

\section{Larger Funding Pools With Longer Funding Cycles}

The co-production of knowledge through transdisciplinary teams requires a higher level of effort for proposal writers and a commitment to engagement among the project team. Lengthening proposal submission timelines, as appropriate, could accommodate and encourage the depth and scale of engagement necessary to fully scope the dimensions of the research proposed. Funding agencies could also incentivize more holistic R2A projects by providing larger funding pools. The provision of larger funding pools underlies many of the facilitating factors that arose from this study, e.g., iterative communication that funds stakeholder workshops throughout the project duration, transparent planning and support for project team planning team meetings, or the ability to fund new graduate students.

\section{CONCLUSION}

We conducted 52 interviews with RCs and ELs from across the Sea Grant Network to answer three main questions. We found that (1) projects identified as successful were about equally as likely to have started as scientific inquiry as stakeholder need; (2) out of the five common R2A deliverables identified (tool operationalization, information production, informing policy, behavioral change, and attitude change), tool operationalization was identified the most often while attitude change the least; and (3) facilitating factors such as platforms for partnerships, iterative communication, transparent planning, clear examples of R2A, and graduate student involvement are all being utilized by the Sea Grant network.

While the value of actionable science is increasingly recognized, programs funding research struggle to bridge the gap between research and application. The strategies for enabling R2A discussed in this study are not only relevant for funding organizations like Sea Grant, but for other agencies and research institutions as well. Academic researchers could benefit from more training and understanding of the R2A process, as outlined in this paper because training in communication, engagement, and outreach can motivate researchers to participate in actionable science more often (Lemos and Morehouse, 2005). 
Universities can incentivize a more frequent and higher quality stakeholder engagement from their researchers by providing recognition and promotion for such efforts (Dilling and Lemos, 2011). Transdisciplinary co-production of knowledge takes longer to reach an identifiable outcome, which is often not as easily quantified as a publication in a high impact journal (Nyden, 2003).

One of our facilitating factors is providing clear examples of R2A; we have endeavored to do just that by presenting locally scaled case studies that demonstrate practices that have transferability to programs beyond Sea Grant. The five facilitating factors are intertwined, with each supported by communicative partnerships to form transdisciplinary teams to address complex environmental problems in a changing world. Because of the organizational, geographical, and resource diversity among the Sea Grant programs, there will never be a single prescriptive model that works for every program. Additionally, there are many challenges to implementing change such as lack of resources and professional or cultural resistance but, in the face of unprecedented climatic change and exploited resources, it is imperative that the scientific community prioritize solution-oriented and socially conscious science.

\section{DATA AVAILABILITY STATEMENT}

The raw data supporting the conclusions of this article will be made available by the authors, without undue reservation.

\section{REFERENCES}

Arnstein, S. R. (1969). A ladder of citizen participation. J. Am. Institute Plan. 35, 216-224. doi: 10.1080/01944366908977225

Bernstein, J. H. (2015). Transdisciplinarity: a review of its origins, development, and current issues. J. Res. Pract. 11:R1.

Cash, D. W., Clark, W. C., Alcock, F., Dickson, N. M., Eckley, N., Guston, D. H., et al. (2003). Knowledge systems for sustainable development. Proc. Natl. Acad. Sci. U.S.A. 100, 8086-8091. doi: 10.1073/pnas. 1231332100

Dilling, L., and Lemos, M. C. (2011). Creating usable science: opportunities and constraints for climate knowledge use and their implications for science policy. Glob. Environ. Change 21, 680-689. doi: 10.1016/j.gloenvcha.2010.11.006

Gemme, B., and Gingras, Y. (2012). Academic careers for graduate students: a strong attractor in a changed environment. High. Educ. 63, 667-683. doi: 10. 1007/s10734-011-9466-3

Gibbons, M. (2000). Mode 2 society and the emergence of context-sensitive science. Sci. Publ. Pol. 27, 159-163. doi: 10.3152/147154300781782011

Hering, J. G. (2016). Do we need "more research" or better implementation through knowledge brokering? Sustain. Sci. 11, 363-369. doi: 10.1007/s11625-0150314-8

Hilborn, R. (2007). Defining success in fisheries and conflicts in objectives. Mar. Pol. 31, 153-158. doi: 10.1016/j.marpol.2006.05.014

Iwamoto, M. M., Dorton, J., Newton, J., Yerta, M., Gibeaut, J., Shyka, T., et al. (2019). Meeting regional. coastal and ocean user needs with tailored data products: a stakeholder-driven process. Front. Mar. Sci. 6:290. doi: 10.3389/ fmars.2019.00290

Lang, D. J., Wiek, A., Bergmann, M., Stauffacher, M., Martens, P., Moll, P., et al. (2012). Transdisciplinary research in sustainability science: practice, principles, and challenges. Sustain. Sci. 7, 25-43. doi: 10.1007/s11625-011-0149-x

\section{AUTHOR CONTRIBUTIONS}

HJ contributed to the methodology, investigation, formal analysis, writing of original draft, and editing. RB contributed to the conceptualization, supervision, and editing. AK contributed to the formal analysis, resources, and editing. ER contributed to the conceptualization. All authors contributed to the article and approved the submitted version.

\section{FUNDING}

This manuscript was funded in part with Federal funds under award number NA19OAR4170004 from the National Oceanic and Atmospheric Administration's National Sea Grant College Program, United States Department of Commerce. The statements, findings, conclusions, and recommendations are those of the author(s) and do not necessarily reflect the views of the National Sea Grant College Program or the United States Department of Commerce.

\section{ACKNOWLEDGMENTS}

We would like to thank Louisiana Sea Grant and Louisiana State University for their institutional support of this project and all of the Research Coordinators and Extension Leads from the state Sea Grant programs for their time and input during the interview process.

Lemos, M. C., and Morehouse, B. J. (2005). The co-production of science and policy in integrated climate assessments. Glob. Environ. Change 15, 57-68. doi: 10.1016/j.gloenvcha.2004.09.004

Matso, K. E., and Becker, M. L. (2014). What can funders do to better link science with decisions? case studies of coastal communities and climate change. Environ. Manage. 54, 1356-1371. doi: 10.1007/s00267-014-0347-2

Miller, C. A., and Wyborn, C. (2018). Co-production in global sustainability: histories and theories. Environ. Sci. Policy 113,

National Oceanic and Atmospheric Administration (2017). NAO 216-105B: Policy on Research and Development Transitions. Washington, DC: National Oceanic and Atmospheric Administration.

National Research Council (2006). Linking Knowledge with Action for Sustainable Development: The Role of Program Management - Summary of a Workshop. Washington, DC: National Academies Press, doi: 10.17226/1 1652

National Sea Grant Office (2000). Fundamentals of a Sea Grant Extension Program. New York, NY: National Sea Grant Office.

National Sea Grant Office (2019). Sea Grant Research. New York, NY: National Sea Grant Office.

Nelson, M. C., Ingram, S. E., Dugmore, A. J., Streeter, R., Peeples, M. A., McGovern, T. H., et al. (2016). Climate challenges, vulnerabilities, and food security. Proc. Natl. Acad. Sci U.S.A.. 113, 298-303. doi: 10.1073/pnas.1506494113

Nguyen, T. T. X., Bonetti, J., Rogers, K., and Woodroffe, C. D. (2016). Indicatorbased assessment of climate-change impacts on coasts: a review of concepts, methodological approaches and vulnerability indices. Ocean Coast. Manag. 123, 18-43. doi: 10.1016/j.ocecoaman.2015.11.022

Nyden, P. (2003). Academic incentives for faculty participation in communitybased participatory research. J. Gen. Intern. Med. 18, 576-585. doi: 10.1046/j. 1525-1497.2003.20350.x 
Riley, C., Matso, K., Leonard, D., Stadler, J., Trueblood, D., and Langan, R. (2011). How research funding organizations can increase application of science to decision-making. Coast. Manag. 39, 336-350. doi: 10.1080/08920753.2011. 566117

Rittel, H. W. J., and Webber, M. M. (1973). Dilemmas in a general theory of planning. Policy Sci. 4, 155-169. doi: 10.1007/bf01405730

Schaffner, L. C., Hartley, T. W., and Sanders, J. G. (2016). Moving Forward: 21st Century Pathways to Strengthen the Ocean Science Workforce Through Graduate Education and Professional Development. Grad. Educ. Ocean Sci. 29, 36-43. doi: 10.5670/oceanog.2016.09

Stokes, D. E. (2011). Pasteur's Quadrant: Basic Science and Technological Innovation. Washington, DC: Brookings Institution Press.

Stott, P. (2016). How climate change affects extreme weather events. Science 352, 1517-1518. doi: 10.1126/science.aaf7271

Van Aken, J. E. (2005). Management research as a design science: articulating the research products of mode 2 knowledge production in management. Br. J. Manag. 16, 19-36. doi: 10.1111/j.1467-8551.2005.00 437.x

van Kerkhoff, L., and Lebel, L. (2006). Linking knowledge and action for sustainable development. Annu. Rev. Environ. Resour. 31, 445-477. doi: 10.1146/annurev. energy.31.102405.170850
West, S., van Kerkhoff, L., and Wagenaar, H. (2019). Beyond "linking knowledge and action": towards a practice-based approach to transdisciplinary sustainability interventions. Policy Stud. 40, 534-555. doi: 10.1080/01442872. 2019.1618810

Whitmer, A., Ogden, L., Lawton, J., Sturner, P., Groffman, P. M., Schneider, L., et al. (2010). The engaged university: providing a platform for research that transforms society. Front. Ecol. Environ. 8:314-321. doi: 10.1890/09 0241

Yin, R. K. (1981). The case study as a serious research strategy. Knowledge 3, 97-114. doi: $10.1177 / 107554708100300106$

Conflict of Interest: The authors declare that the research was conducted in the absence of any commercial or financial relationships that could be construed as a potential conflict of interest.

Copyright (c) 2021 Jones, Briggs, Krepp and Rohring. This is an open-access article distributed under the terms of the Creative Commons Attribution License (CC BY). The use, distribution or reproduction in other forums is permitted, provided the original author(s) and the copyright owner(s) are credited and that the original publication in this journal is cited, in accordance with accepted academic practice. No use, distribution or reproduction is permitted which does not comply with these terms. 